\title{
EFECTOS EXTINTIVOS DE UN CONTRATO DE TRABAJO DERIVADOS DE LA EJECUCIÓN DE ACTOS, OMISIONES O IMPRUDENCIAS TEMERARIAS*
}

[The Effects of the Termination of and Employment Contract As a Result of Acts, Omissions or Reckless Imprudence]

\author{
Pedro IrUReTa URIARTE** \\ Universidad Alberto Hurtado, Santiago de Chile
}

\begin{abstract}
RESUMEN
ABSTRACT

El Código del Trabajo chileno san-

The Chilean Labor Code sanctions ciona como justa causa de extinción contractual los actos, omisiones o imprudencias temerarias que ejecute el trabajador, y que afecten a la seguridad $o$ al funcionamiento del establecimiento, a la seguridad o a la actividad de los trabajadores, o a la salud de éstos. Se trata de una causal históricamente asociada a The Chilean Labor Code sanctions the acts, omissions or reckless imprudence by an employee affecting the safety or the operation of the premises, the safety or the employees' work activity or health as fair grounds to terminate a contract. This is a cause historically related to the duties of corporate health and safety, with an emphasis on fault rather
\end{abstract}

RECIBIDO el 29 de abril y ACEPTADO el 8 de mayo de 2015

* El presente trabajo se inscribe dentro del proyecto de investigación FONDECYT $N^{\circ}$ 1140993, titulado: "La configuración de los elementos centrales de las causas disciplinarias de extinción del contrato de trabajo", ejecutado por el autor en calidad de investigador responsable.

** Licenciado en derecho por la Pontificia Universidad Católica de Chile. Doctor en derecho por la Universidad Complutense de Madrid. Profesor titular de derecho del trabajo de la Universidad Alberto Hurtado. Correo electrónico: piruret@uahurtado.cl. 
los deberes de higiene y seguridad en la empresa, y con énfasis en la culpabilidad más que en el dolo del agente provocador. No obstante, su alcance ha terminado siendo más amplio, desbordando los hechos meramente culposos. Lo que prevalece, es que la circunstancia imputada afecte bienes jurídicos relevantes tanto para el empleador como para los trabajadores.

Palabras clave

Extinción del trabajo - Despido Imprudencias temerarias. than on intention of the agent. However, its scope ended up being wider, beyond the unintentional acts. What prevails is that the act attributed affects pertinent legal rights for both the employer and the employees.

\section{KEYWORDS}

Termination of the employment contract - Dismissal - Reckless imprudence.

\section{INTRODUCCIÓN}

Dentro del amplio cúmulo de supuestos extintivos del contrato de trabajo que consagra el Código del Trabajo chileno, destaca una norma específica referida a las conductas (incluso culposas) del trabajador y que afecten la seguridad de la empresa o de las personas que en ella trabajan. En efecto, el artículo $160 \mathrm{~N}^{\circ} 5 \mathrm{CT}$. ha establecido que el contrato de trabajo termina, sin derecho a indemnización, en todos aquellos casos en que el trabajador ejecute "actos, omisiones o imprudencias temerarias que afecten a la seguridad o al funcionamiento del establecimiento, a la seguridad o a la actividad de los trabajadores, o a la salud de éstos".

La norma en comento no es nueva en nuestra legislación. Ya en el año 1924, el artículo $5 \mathrm{~N}^{\circ} 8$ de la Ley $\mathrm{N}^{\circ} 4.053$ señalaba que el contrato de trabajo concluía por las causales generales de expiración y, en especial, "por actos $u$ omisiones que afecten a la salud o a la seguridad de los obreros o a la seguridad del establecimiento". La misma lógica siguió en su momento el artículo $9 \mathrm{~N}^{\circ} 8 \mathrm{CT}$. 1931, con la salvedad no menor de que este último texto legal incorporó dentro de la causal la hipótesis de las imprudencias temerarias. De esta forma, el Código de 1931 concluyó que el contrato podía terminar "por actos, omisiones e imprudencias temerarias que afecten a la seguridad del establecimiento o de los obreros o a la salud de éstos". La misma redacción mantuvo con posterioridad el artículo $2 \mathrm{~N}^{\circ} 4$ de la Ley $N^{\circ} 16.455$, de 1966, aun cuando reemplazó el término obrero por la expresión más genérica de trabajador ${ }^{1}$.

${ }^{1}$ La causal que se comenta no fue mantenida ni por el Decreto-ley $\mathrm{N}^{\circ} 2.200$, de 1978, ni por el Código del Trabajo de 1987. La única referencia genérica vinculada a 
Durante toda esta etapa histórica, la causal a la cual hacemos referencia no motivó mayor desarrollo ni doctrinario ni jurisprudencial. A pesar de ello, existía un cierto consenso argumental en orden a que la hipótesis extintiva se vinculaba con la eventual infracción de las disposiciones de orden, seguridad, salud e higiene, con preceptos sobre trabajo de menores y de las mujeres, con las directrices de trabajo nocturno y en general con "cualquier disposición legal o reglamentaria dictada con el objeto de velar por la seguridad en las faenas y la salud de obreros y empleados"2. De esta manera, durante este período histórico un trabajador incurría en esta causal cuando se presentaba a trabajar aquejado de enfermedades infecto-contagiosas susceptibles de transmitirse con gran facilidad; cuando omitía dar cuenta inmediata de desperfectos observados en las maquinarias de la empresa; o cuando se faltaba a la obligación de mantener aseada y en perfectas condiciones de funcionamiento las instalaciones industriales.

Restaurado el sistema democrático, en el año 1990, la Ley $\mathrm{N}^{\circ} 19.010$ restableció la causal en términos prácticamente iguales a los que se consagraban en la antigua Ley $\mathrm{N}^{\circ} 16.455$. La orientación preceptiva era bastante clara jurídicamente, en el sentido de que se intentaba proteger dos tipos de bienes: la seguridad o el funcionamiento del establecimiento donde se prestan los servicios, y la seguridad, actividad y salud de los trabajadores ${ }^{3}$. Desde luego, se buscaba centrar la hipótesis extintiva en cuestiones estrictamente laborales que se diferenciaran de otras figuras de orden más propiamente penal ${ }^{4}$.

En el presente artículo se plantean los elementos centrales de esta específica causa disciplinaria de despido, su contenido fundamental, y las dificultades de implementación que ella presenta.

este tipo de conducta, y que podría encontrarse en dichos textos, es la causal recogida en ambas normativas relativa a la "comisión de actos que produzcan la destrucción de materiales, instrumentos o productos de trabajo o mercaderias, o disminuyan su valor $o$ causen su deterioro". No obstante, esta redacción estaba más enfocada a la ejecución de actos dolosos y no tanto a la provocación de imprudencias temerarias.

${ }^{2}$ Véase: Davis, Pedro, Terminación del contrato de trabajo (Santiago, Editorial Bibliográfica Chilena, s.d), p. 42.

${ }^{3}$ Véase: Walker Errázuriz, Francisco, Terminación del contrato de trabajo (Santiago, Cepet, 1990), pp. 59-60.

${ }^{4}$ Así consta de la Historia de la Ley No 19.010 (Primer Informe de la Comisión de Constitución, Legislación, Justicia y Reglamento, y de la Comisión de Trabajo y Previsión Social, unidas, del Senado, de 8 de agosto de 1990), pp. 31 y 32. 


\section{LOS ELEMENTOS CENTRALES DE LA HIPÓTESIS EXTINTIVA}

\section{La conducta reprochada al trabajador: actos, omisiones o imprudencias temerarias.}

El artículo $160 \mathrm{~N}^{\circ} 5 \mathrm{CT}$. comienza describiendo las conductas indebidas del trabajador. De manera genérica, se hace referencia a los actos, omisiones o imprudencias temerarias. Los términos usados tienen una clara connotación penal, aun cuando laboralmente deben ser vistos de manera más amplia y flexible. Por ello, no resultaría aceptable que se pretenda trasladar estas figuras al ámbito laboral, desde una mera perspectiva jurídicopenal, ya que ello supondría en la práctica asimilar los comportamientos reprochados con una especie de delito (cuestión que desde luego no calza completamente con la intención que tuvo el legislador al consagrarla). En la lógica de los autores de la Ley No 19.010, y que sirvió de soporte al Código actual, estaba muy presente la idea de separar conductas meramente delictuales de aquellas que suponían una infracción laboral propiamente tal.

En este contexto, el Código comienza reprochando los actos. Estos a c t o s a los que alude la norma legal presuponen una acción del trabajador, una actividad de hecho ${ }^{5}$, en el sentido que él ejecuta un movimiento corporal que trae como consecuencia un determinado resultado o un cambio en el mundo exterior ${ }^{6}$. Ese movimiento corporal refleja una actividad externa dirigida por la voluntad del trabajador a un objetivo determinado ${ }^{7}$. Y esa acción, por cierto, no es neutra; por el contrario, para que se produzca el reproche laboral resulta esencial que ocurra una determinada consecuencia. De allí que el legislador sancione en primer término una conducta positiva del trabajador, reflejada en una consecuencia no deseada por el ordenamiento jurídico y que afecta a bienes jurídicos relevantes.

La o m i s i ó n, por su parte, debe ser configurada como la no ejecución por parte del trabajador de aquello a lo que legal o contractualmente estaba obligado a realizar, encontrándose desde luego en condiciones de poder hacerlo ${ }^{8}$. Como se puede observar, la omisión que se reprocha no

${ }^{5}$ Véase: Soto Calderón, Juan Carlos, Derecho penal del trabajo (Santiago, Editorial Jurídica de Chile, 1961), p. 121.

${ }^{6}$ Véase: Labatut Glena, Gustavo, Derecho penal (7a edición, Santiago, Editorial Jurídica de Chile, 1996), I, p. 70

${ }^{7}$ Véase: Garrido Montt, Mario, Derecho penal (4a edición, Santiago, Editorial Jurídica de Chile, 2010), II, pp. 235 y ss.

${ }^{8}$ Ibíd., p. 12. Como señala Montoya Melgar, Alfredo, Dirección y control de la actividad laboral, en Borrajo DaCruz, Efrén (director), Comentarios a las leyes laborales. El Estatuto de los Trabajadores (Madrid, Edersa, 1985), V, pp. 119-120: 
es un mero $\mathrm{n}$ o $\mathrm{h}$ a c e r a $\mathrm{g}$ o; más bien, es no realizar una conducta pudiendo haberlo hecho, y a pesar que en virtud del contrato y de la ley se habría esperado que sí se realizara efectivamente un determinado comportamiento. Por ello, para que se produzca la omisión resulta esencial que el trabajador se encuentre ante un imperativo de cumplimiento de una conducta, cuestión que permite separar la simple existencia de una obligación del no cumplimiento correspondiente?

Para que el a c t o o la o $\mathrm{m}$ i s i ó $\mathrm{n}$ sean constitutivos de infracción laboral, resulta indispensable que la conducta reprochada haya a f e c t a d o los bienes jurídicos a los que se refiere el Código (v. gr., la seguridad o el funcionamiento del establecimiento, o la seguridad, actividad o salud de los trabajadores). Esta exigencia deja al descubierto la antijuridicidad de la conducta, siempre y cuando dicho comportamiento no haya sido permitido por el contrato o por el ordenamiento legal. Con todo, en ambos casos, la ley laboral parece partir de la base que la conducta reprochada se llevó a cabo con intención ${ }^{10}$ y con clara comprensión de lo que se estaba ejecutando. Es decir, los actos u omisiones que reprocha el artículo $160 \mathrm{~N}^{\circ}$ 5 CT. se vinculan en parte con una mínima conciencia de la ilicitud del

“[...] la reducción (y, a fortiori, la anulación) del rendimiento debido no pueden imputarse a negligencia (menos aún a culpabilidad dolosa) del trabajador cuando medie un acto del empresario al que deba atribuirse la disminución del rendimiento. El razonamiento es obvio: el trabajador no responde de los actos del empresario que obstaculizan o vedan la prestación laboral".

${ }^{9}$ En un caso en particular, la jurisprudencia sancionó tanto al instigador como al trabajador obligado a realizar una determinada conducta. Así se puede observar en la sentencia de la Corte Suprema, de 8 de agosto de 2012, en Revista Fallos del Mes, 558 (2012), pp. 647 ss., en que de acuerdo con los criterios de la Corte "los hechos establecidos en los motivos décimo octavo, vigésimo quinto y trigésimo segundo de la sentencia de primer grado son suficientes para estimar que los demandados incurrieron en actos y omisiones temerarias que afectaron el funcionamiento del establecimiento al haber incitado a otros conductores a detener o estacionar los buses, taxibuses y furgones de la empresa demandante, siguiendo los conductores sus instrucciones, suspendiendo y obstaculizando el tránsito de vehiculos con trabajadores de las empresas Astilleros Asmar de Talcahuano y Masisa Coronel y alumnos del establecimiento Kingston College, provocando un retraso en el servicio de veinte a treinta minutos, lo que impidió a la empresa desarrollar sus actividades con normalidad y cumplir oportunamente con el servicio de transporte de pasajeros prestado a las entidades indicadas. Este hecho reúne las condiciones a las que se hizo referencia en el considerando sexto de esta sentencia, toda vez que se ha afectado seriamente el funcionamiento de la empresa".

${ }^{10}$ Véase, en la misma línea: Thayer Arteaga, William - Novoa Fuenzalida, Patricio, Manual de derecho del trabajo (3a edición, Santiago, Editorial Jurídica de Chile, 1998), III, p. 58. En el plano jurisprudencial, véase, además, la sentencia de la Corte de Apelaciones de Santiago, de 16 de abril de 1998, en Gaceta Jurídica, 214 (1998), p. 188. 
comportamiento, de modo tal que el trabajador ejecutó la conducta con intención y voluntad de a f e c t a r . Sólo de esa manera puede explicarse la estructura que utiliza este numeral, el cual distingue entre figuras dolosas (actos u omisiones) y culposas (imprudencias temerarias). Más aun, esta distinción se explica si se considera una cierta degradación de gravedad entre los actos, las omisiones y las imprudencias temerarias ${ }^{11}$.

Consecuente con lo anterior, el Código también sanciona las figuras culposas. En efecto, cuando se hace referencia a las i m p r u d e n c i a s $\mathrm{t}$ e $\mathrm{m}$ e $\mathrm{r}$ a $\mathrm{r}$ i a s se intenta vincular la acción u omisión dentro del marco propio de la imprudencia cuestión que permite concluir que tanto el dolo como la culpa están incorporados en esta específica hipótesis extintiva (aun cuando no se requiere en todos los casos de la concurrencia de un dolo o intención específica de afectar) ${ }^{12}$. No obstante, resulta evidente que el Código no sanciona cualquier imprudencia, sino que aquella que tiene el carácter de temeraria, equiparando la imprudencia con la culpa lata. Siguiendo a la jurisprudencia, la imprudencia temeraria deja al descubierto una conducta extremadamente i m prudente o

${ }^{11}$ Excepcionalmente, parte de la jurisprudencia ha concluido que el carácter temerario se exige tanto de los actos u omisiones, como de las imprudencias. Así lo señala, por ejemplo, la sentencia de la Corte de Apelaciones de Concepción, de 17 de diciembre de 2014 (causa ingreso corte No 326-2014, en www.poderjudicial.cl): "Que, a su vez, analizando la causal de despido del artículo $160 \mathrm{~N}^{\circ} 5$ del Código del ramo, la que estableció en el considerando $9^{\circ}$ que los requisitos copulativos para la configuración de ésta eran los siguientes: 1) que se ejecuten actos, omisiones o imprudencias; 2) que éstas sean temerarias; y 3) que se afecte o exista la posibilidad de afectar los bienes jurídicos por ella protegidos, es decir, la seguridad o funcionamiento del establecimiento, la seguridad o actividad de los trabajadores o la salud de éstos". Nosotros no compartimos este criterio, ya que la estructura de la causal deja al descubierto que sólo de las imprudencias se predica el carácter temerario. En los demás casos, el Código sólo exige que concurra un acto u omisión cuyo resultado sea sancionado por el artículo 160 No 5 CT.

${ }^{12}$ Véase: sentencia de la Corte Suprema, de 27 de agosto de 2007 (causa ingreso corte $\mathrm{N}^{\circ}$ 3916-2006, en www.poderjudicial.cl). A mayor abundamiento, véase sentencia de la Corte de Apelaciones de Valparaíso, de 2 de abril de 2015 (causa ingreso corte No 85-2015, en www.poderjudicial.cl): “Tercero: Que, como se lee en el considerando séptimo de la sentencia recurrida, se identifican los conceptos de imprudencia temeraria y dolo, lo que no es procedente pues ambos conceptos atingen, respectivamente, a la culpa y el dolo, teniendo ambos requisitos, exigencias y características que los diferencian totalmente. Cuando se actúa con culpa, aunque ella constituya una imprudencia temeraria no existe en el sujeto activo una intencionalidad [...]". 
con una negligencia considerable ${ }^{13}$, que se acredita de forma clara y precisa ${ }^{14}$.

La imprudencia temeraria tiene una clara traducción en el ámbito penal. Para dicha disciplina, este tipo de figuras se conectan con un grado de mayor intensidad de culpa susceptible de sanción. "Es la omisión de aquel cuidado que puede exigirse a las personas menos diligentes al realizar una actividad creadora de riesgos; consiste en la inobservancia de la diligencia más elemental y se equipararía al concepto civil de culpa lata, no observar lo que en el caso concreto hubiese resultado evidente a cualquiera" ${ }^{15}$. Con todo, cabe hacer presente que en el contexto del Código del Trabajo la invocación parece ser más flexible, poniendo el acento en comportamientos culposos más exigentes desde el punto de vista de su calificación. Así ocurrió, por ejemplo, en el caso resuelto por la sentencia de la Corte Suprema, de 23 de mayo de 2013, en que se consideró justificado el despido de un trabajador que "accionó un encendedor para prender fuego a las manos de otro trabajador, quien, en forma previa a consumir sus alimentos, se las habia rociado con alcohol gel, resultando éste con los vellos de las manos quemados, calificándose el obrar del actor como una imprudencia temeraria inexcusable al exponer a un compañero de trabajo a una situación de alto riesgo, dando

${ }^{13}$ Véase la sentencia de 22 de enero de 2003, en Revista Fallos del Mes, 506 (2003), p. 5209. Y en el mismo fallo, se agrega: "En la especie, tratándose de un conductor de camiones, con una experiencia de más de cuatro años en la actividad, es lógico admitir que debió adoptar las medidas pertinentes para evitar el accidente en el cual participó y, al no hacerlo, actuó de manera extremadamente imprudente, pues se trataba de prever a lo menos que la grúa pescante que llevaba su vehiculo, al estar en posición semilevantada, era de superior altura al paso bajo nivel que debia cruzar, por ello era necesario ubicarla de manera de permitir el paso sin exponerse a daño alguno". En igual sentido, sentencia de la Corte de Apelaciones de Rancagua de 25 de noviembre de 2014 (causa ingreso corte No 116-2014, en www.poderjudicial.cl): "En efecto, la experiencia adquirida por el actor, desde que ingresó a la empresa demandada, debió conducirle a prever la envergadura de su actuar y a tomar las medidas pertinentes para evitar la ocurrencia de un accidente, lo que al no hacerlo, no obstante las capacitaciones entregadas, se desprende con mediana claridad que su conducta fue extremadamente imprudente, más aún cuando se trabaja en una zona, como es la mina El Teniente, que exige de todos sus trabajadores el máximo de sentido común y prudencia".

${ }^{14}$ Véase sentencia de la Corte de Apelaciones de Santiago de 9 de enero de 1997, en Gaceta Jurídica, 199 (1997), p. 177: "1) Que atendida la gravedad de la causal contemplada en el $N^{\circ} 5$ del artículo $160 \mathrm{CT}$., cuando ella sirve de fundamento para poner término a una relación laboral ha de acreditarse de manera clara y precisa el carácter 'temerario' de la conducta del trabajador [...]”.

${ }^{15}$ Véase: Garrido MontT, Mario, Derecho penal, cit. (n. 7), p. 173. Véase también, pero en el ámbito laboral, CABANELLAS, Guillermo, Tratado de derecho laboral (3a edición Buenos Aires, Heliasta, 1988), II, 3, p. 189. 
con ello por configurada la causal de despido del artículo $160 \mathrm{~N}^{\circ} 5$ del Código del Trabajo"16.

Lo expuesto obliga a desterrar de la hipótesis del artículo 160 Nº 5 CT., todas aquellas conductas meramente negligentes, y que son menos intensas que la imprudencia temeraria ${ }^{17}$. Lo que ocurre es que la negligencia es una

${ }^{16}$ Véase sentencia de la Corte Suprema, de 23 de mayo de 2013 (causa ingreso corte $\mathrm{N}^{\circ}$ 292-2013, en www.poderjudicial.cl). En igual sentido, sentencia de la Corte Suprema de 8 de agosto de 2012, la cual concluyó que para configurar la causal los hechos ejecutados por el dependiente deben ser extremadamente imprudentes o con una negligencia considerable. "No se requiere entonces una intencionalidad especial, sino un olvido inexcusable de las precauciones que la prudencia vulgar aconseja y que conduce a la realización de hechos que, de mediar malicia, constituirían malicia", en Revista Fallos del Mes, 558 (2012), pp. 647 ss. En igual sentido, sentencia de la Corte de Apelaciones de Rancagua, de 25 de noviembre de 2014 (causa ingreso corte No 116-2014, en www.poderjudicial.cl): "Que, la temeridad que exige el artículo 160 número 5 CT., implica que el trabajador se exponga conscientemente a peligros o riesgos, sin medir las consecuencias, peligros, no tan solo para él o sus compañeros de trabajo, sino que también para los bienes materiales del empleador. No se requiere entonces una intencionalidad especial, sino que un olvido inexcusable de las precauciones que la prudencia común aconseja y que conduce a la realización de hechos".

${ }^{17}$ Véase la tesis seguida por la misma sentencia de la Corte Suprema, de 23 de mayo de 2013 (causa ingreso corte $\mathrm{N}^{\circ}$ 292-2013, en www.poderjudicial.cl): "Sexto: Que esta causal, contemplada en el $N^{\circ} 5$ del artículo $160 \mathrm{CT}$., supone en primer término que los hechos ejecutados por el dependiente sean extremadamente imprudentes o con una negligencia considerable. No se requiere entonces una intencionalidad especial, sino un olvido inexcusable de las precauciones que la prudencia común aconseja y que conduce a la realización de hechos que, de mediar malicia, constituirian delito". En igual sentido, sentencia de la Corte Suprema, de 22 de enero de 2003, en Revista de Derecho y Jurisprudencia y Gaceta de los Tribunales, 100 (2003), sección 3a p. 4: “Que en lo relativo a la primera causal citada, ello supone que los actos ejecutados por el dependiente sean de naturaleza temeraria, es decir, extremadamente imprudente o con una negligencia considerable"; sentencia de la Corte Suprema, de 28 de abril de 2005, en Gaceta Jurídica, 298 (2005), p. 254: "Que en lo relativo a la primera causal citada (160 N 5), ella supone que los hechos ejecutados por el dependiente sean de naturaleza temeraria, esto es, extremadamente imprudentes o con una negligencia considerable"; sentencia de la Corte Suprema de 27 de agosto de 2007 (causa ingreso corte № 3916-2010, en www.poderjudicial.cl): "Séptimo: Que la causal de despido en estudio consiste en: 'actos, omisiones o imprudencias temerarias que afecten a la seguridad o al funcionamiento del establecimiento, a la seguridad o a la actividad de los trabajadores, o a la salud de éstos'. En este sentido, cabe señalar que el Diccionario de la Lengua Española de la Real Academia (Vigésima Primera edición, página 1149, Tomo In), define la expresión imprudencia temeraria, como 'punible e inexcusable negligencia con olvido de las precauciones que la prudencia vulgar aconseja, la cual conduce a ejecutar hechos que, a mediar malicia en el actor, serían delitos'"; sentencia de reemplazo de la Corte Suprema de 14 de julio de 2010 (causa ingreso corte $\mathrm{N}^{\circ}$ 1606-2010, en www.poderjudicial.cl): "Primero: Que la causal de caducidad del contrato de trabajo invocada en contra del actor, con- 
distracción estándar que se explica fundamentalmente por la concurrencia de un descuido o error; la imprudencia temeraria, no obstante, deja al descubierto un cierto estado de voluntad que se asimila con la culpa grave $^{18}$. Es decir, el grado de responsabilidad es notoriamente mayor en el supuesto de la imprudencia temeraria, ya que de mediar malicia esa misma conducta se asimilaría a un delito ${ }^{19}$. Eso explica que, en algunos casos, la misma jurisprudencia haya relacionado las negligencias simples a supuestos propios de accidentes, sin consecuencia infraccional ${ }^{20}$. Por el contrario, sí

templada en el $N^{\circ} 5$ del artículo $160 \mathrm{CT}$., consistente en haber incurrido éste en actos, omisiones o imprudencias temerarias que afecten a la seguridad o al funcionamiento del establecimiento, a la seguridad, actividad o salud de los trabajadores, supone, en primer término, que los hechos ejecutados por aquél sean extremadamente imprudentes o con una negligencia considerable. No se requiere, entonces, una intencionalidad especial, sino un olvido inexcusable de las precauciones que la prudencia vulgar aconseja y que conduce a la realización de hechos que, de mediar malicia, constituirian delito"; y sentencia de la Corte Suprema, de 8 de agosto de 2012, en Revista Fallos del Mes, 558 (2012), pp. 647 ss.: "Sexto: Que esta causal contemplada en el $N^{\circ} 5$ del artículo 160 CT., supone en primer término, que los hechos ejecutados por el dependiente sean extremadamente imprudentes o con una negligencia considerable. No se requiere, entonces, una intencionalidad especial, sino un olvido inexcusable de las precauciones que la prudencia vulgar aconseja y que conduce a la realización de hechos que, de mediar malicia, constituirían delito". Véase también y a mayor abundamiento sentencia de la Corte de Apelaciones de Santiago de 9 de enero de 1997, en Gaceta Jurídica, 199 (1997), p. 177, según la cual la circunstancia de no emitir una boleta de compraventa no configura la causal del artículo $160 \mathrm{~N}^{\circ} 5 \mathrm{CT}$., aun cuando ello haya supuesto que el empleador fuese sancionado por el Servicios de Impuestos Internos.

${ }^{18}$ Véase: sentencia de la Corte Suprema, de 13 de agosto de 2002, en Gaceta Jurídica, 266 (2002), p. 172, según la cual para que esta causal se configure, el legislador ha exigido más que un error en las funciones propias del cargo, se requiere de una acción u omisión dolosa o a lo menos de una negligencia considerable. Véase también sentencia de la Corte Suprema de 21 de septiembre de 2012 (causa ingreso corte No 2197-2010, en www.poderjudicial.cl): “La imprudencia consiste entonces en un obrar sin aquel cuidado que según la experiencia corriente debe tenerse en la realización de ciertos actos; es un comportamiento defectuoso resultante de una respuesta al estímulo que la provoca sin que el sujeto haya realizado la suficiente valoración sobre la oportunidad o inoportunidad, conveniencia o inconveniencia de la reacción $y$, desde luego, sin la suficiente graduación de la intensidad de su efecto. Asi vemos que se trata de una falla de la esfera intelectiva del sujeto, que lo lleva a desplegar una conducta sin las precauciones debidas en el caso concreto".

${ }^{19}$ Véase la sentencia de la Corte Suprema de 23 de mayo de 2013 (causa ingreso corte No 292-2013, en www.poderjudicial.cl).

${ }^{20}$ Véase: sentencia de la Corte Suprema de 14 de marzo de 2006 (causa ingreso corte $\mathrm{N}^{\circ}$ 6658-2006, en www.poderjudicial.cl). En este caso en particular, el trabajador había sido despedido por su empleador bajo el argumento que aquél sería responsable del accidente laboral sufrido por otra trabajadora, quien resultó con es- 
ha considerado propios de esta causal imprudencias tales como concurrir al manejo de una máquina excavadora en notorio estado de ebriedad ${ }^{21}$, sobredimensionar o exagerar los costos del establecimiento ${ }^{22}$, el encender un cigarrillo al lado de un componedor de combustible, e incluso el "discutir e inferir insultos a sus compañeros de trabajo y jefe de turno, durante su jornada laboral, hechos éstos que afectaron el normal funcionamiento de las labores de su empleador" 23 .

Desde luego, la noción de imprudencia temeraria no puede ser homogénea para todos los oficios. Existen cargos que atendida su peligrosidad se le exige al trabajador un mayor celo y cuidado ${ }^{24}$. Eso ocurre, por ejemplo, en el caso de los médicos o profesionales de la salud, en que la imprudencia temeraria se asocia con la idea de impericia para desarrollar su respectiva

guince cervical con once días de licencias médica, toda vez que él habría pateado la silla en que ella se iba a sentar, incurriendo en una broma. Frente a este hecho, la jurisprudencia consideró injustificado el despido estableciendo la diferencia entre un mero accidente y una imprudencia temeraria: "De los requisitos antes referidos y como lo han sostenido reiteradamente nuestros Tribunales de Justicia es menester que la imprudencia exigida para la concurrencia de la causal sea de naturaleza temeraria, esto es, extremadamente imprudente o con negligencia considerable, es decir, con ineptitud mayor o torpeza inexcusable, conducta que por su gravedad debe encontrarse clara y precisamente acreditada, todo lo cual y como resulta obvio se opone a la ocurrencia de un accidente entendido este último como un suceso eventual o acción de que involuntariamente resulta daño para las personas o las cosas según definición del Diccionario de la Lengua Española".

${ }^{21}$ Véase: sentencia de la Corte Suprema de 2 de junio de 2011 (causa ingreso corte $\mathrm{N}^{\circ} 8456-2010$, en www.poderjudicial.cl). Sobre la posibilidad de encuadrar supuestos de ebriedad a la causal del artículo 160 N 5 CT., véase además sentencia de la Corte de Apelaciones de Valdivia de 14 de diciembre de 2012 (causa ingreso corte $\mathrm{N}^{\circ} 140-2012$, en www.poderjudicial.cl). El mismo criterio siguió la jurisprudencia bajo la vigencia de la Ley $\mathrm{N}^{\circ} 16.455$, según consta en la sentencia de la Corte Suprema de 11 de enero de 1973, en Revista de Derecho y Jurisprudencia y Gaceta de los Tribunales, 70 (1971), Sección 3a , p. 1: "Incurre en las causales señaladas en los $N^{\circ}$ 2 y 4 del artículo $2^{\circ}$ de la Ley $N^{\circ} 16.455$ [...], el trabajador respecto del cual se encuentra acreditado que padecía de alcoholismo crónico cuyo estado de intemperancia afecta la seguridad del trabajo que realiza [...]".

${ }^{22}$ Sentencia de la Corte Suprema de 5 de enero de 1994, en Humeres Noguer, Héctor (director), Repertorio de Legislación y Jurisprudencia Chilenas. Código del Trabajo y Leyes Complementarias (Santiago, Editorial Jurídica de Chile, 2002), I, p. 192.

${ }^{23}$ Sentencia de la Corte de Apelaciones de Copiapó, de 28 de marzo de 2012 (causa ingreso corte $\mathrm{N}^{\circ}$ 5-2012, en www.poderjudicial.cl).

${ }^{24}$ Aun cuando la jurisprudencia circunscribió la conducta indebida dentro de la hipótesis del artículo $160 \mathrm{~N}^{\circ} 6 \mathrm{CT}$., véase de todos modos el caso resuelto por la sentencia de la Corte Suprema de 5 de enero de 1998, en Revista de Derecho y Jurisprudencia y Gaceta de los Tribunales, 95 (1998), Sección 3a, p. 1. 
le $\mathrm{x}$ a r t is ${ }^{25}$. Conclusiones similares podrían plantearse respecto de aquellos trabajadores que tienen a su cargo el cuidado de animales feroces que por descuido del trabajador responsable causan daño a otros trabajadores; incluso con respecto de aquellas personas que por su cargo tienen la conducción y cuidado de vehículos de la empresa ${ }^{26}$ o que tienen la calidad de "operador eléctrico y de atmósfera" cuestión que le asignaba la obligación de hacerse cargo del procedimiento de deshielo de cámaras ${ }^{27}$. En el fondo, en todas estas hipótesis la naturaleza del cargo circunscribe el contenido obligacional del trabajador aumentando o disminuyendo el reproche de acuerdo a la diligencia que se espera en una función determinada ${ }^{28}$.

${ }^{25}$ Véase por ejemplo la sentencia de la Corte Suprema de 27 de agosto de 2007 (sentencia de reemplazo) dictada en la causa ingreso corte $\mathrm{N}^{\circ} 3916-2006$, en www. poderjudicial.cl: "Segundo: Que la conducta desarrollada por la actora, en circunstancias que cumplia labores de auxiliar paramédico consistente en haber alterado la composición de solución de formalina, empleada en la esterilización del material reutilizado por pacientes que concurrían a tal centro a efectuar procedimientos de diálisis, al no respetar las indicaciones respecto de su preparación dadas por la empleadora y fijadas, incluso por la autoridad de salud, constituye un acto de tal entidad y gravedad, que han afectado la seguridad y funcionamiento del establecimiento de la demandada, atendida la naturaleza de los servicios que ésta presta, lo que permite justificar el despido de la trabajadora".

${ }^{26}$ Véase: por ejemplo, sentencia de la Corte Suprema de 31 de marzo de 2004, en Gaceta Jurídica, 286 (2004), p. 293. Aun cuando en este caso la causal aplicada para justificar el despido fue la del artículo 160 No 7 CT., de todas formas se validó la sanción de empleador precisamente por las funciones propias del cargo que tenía el trabajador: vendedor con salidas a terreno.

${ }^{27}$ Véase: sentencia de la Corte Suprema de 13 de agosto de 2002, en Gaceta Jurídica, 266 (2002), p. 172: "Séptimo: Que en la presente causa, de la prueba analizada aparece demostrado que el descenso brusco de la temperatura al interior de la cámara $N^{o} 8$ fue lo que causó el desprendimiento de los paneles del techo de la misma, lo que sin lugar a dudas, como explican los técnicos en sus respectivos informes, se debió a un actuar descuidado del actor al efectuar la operación de deshielo encendiendo los evaporadores simultáneamente y no de uno en uno como era su obligación, para lo cual estaba debidamente capacitado y entrenado". Véase también sentencia de la Corte de Apelaciones de Concepción de 6 de septiembre de 2002, en Gaceta Jurídica, 267 (2002), p. 191.

${ }^{28}$ Véase Montoya Melgar, Alfredo, Derecho del trabajo (29a edición, Madrid, Tecnos, 2008), nota n. 94, p. 320. La jurisprudencia ha concluido que la experiencia del trabajador en el ejercicio de un cargo, también debe ser considerada al momento de evaluar una conducta temeraria. Así ocurrió en el caso resuelto por la sentencia de la Corte Suprema de 28 de abril de 2005, en Gaceta Jurídica, 298 (2005), p. 254. El caso en cuestión se refería a un maestro de mantención, con una experiencia de, a lo menos, seis años en la actividad. Según la Corte, "con la instrucción y preparación necesarias, resulta lógico concluir que su actuación fue, a lo menos, temeraria, en la medida que realizó trabajos de electricidad de alta tensión sin adoptar las medidas de seguridad necesarias para tales efectos, arriesgando la vida y la salud de los restantes dependientes de la empresa de manera, además, negligente. La experiencia adquirida debió conducirle 
Por último, cabe tener presente que tanto en las figuras dolosas como culposas, debe partirse de la base que la conducta que se le reprocha al trabajador no tiene justificación y reviste caracteres relevantes de gravedad ${ }^{29}$.

a prever la envergadura de sus actuaciones y en consecuencia, a tomar las medidas pertinentes, las cuales conocía con anterioridad, para evitar la ocurrencia de un accidente que involucrara su propia vida y la de sus compañeros de trabajo y, al no hacerlo, no obstante las especificas instrucciones del empleador, actuó de manera extremadamente imprudente, pues se trataba de prever que la electricidad podía causar heridos y muertes respecto de los cuales, indudablemente, resultaría responsable el demandado, aun cuando en fin no se hayan producido los daños que debieron preverse por el trabajador". En la misma línea, véase sentencia de la Corte Suprema de 22 de enero de 2003, en Revista de Derecho y Jurisprudencia y Gaceta de los Tribunales, 100 (2003), Sección 3a, p. 4: "En la especie, tratándose de un conductor de camiones, con una experiencia de más de cuatro años en la actividad, es lógico admitir que debió adoptar las medidas pertinentes para evitar que conduciendo un camión con grúa pescante semilevantada, de superior altura al paso bajo nivel que debia cruzar, de acceso a la bodega central de la empresa, causara graves daños al camión, por lo que su conducta puede calificarse de extremadamente imprudente"; sentencia de la Corte Suprema de 27 de agosto de 2007 (causa ingreso corte $\mathrm{N}^{\circ}$ 3916-2006, en www.poderjudicial.cl): "Décimo: Que al decidir la sentencia de un modo contrario al expuesto, esto es, que la causal fue injustificada, porque la conducta del actor no ha podido estimarse como temeraria, por no haberse establecido de parte de la actora la existencia de una intención o dolo, sin considerar la gravedad y entidad de los hechos, en el contexto de la labor desarrollada por la actora y la naturaleza de los servicios prestados a los usuarios por la Corte Suprema de 14 de julio de 2010 (causa ingreso corte $N^{\circ}$ 1606-2010, en www.poderjudicial.cl): "Segundo: Que en la especie, tratándose de un conductor de camiones con una experiencia de más de seis años en la actividad, es lógico admitir que debió adoptar las medidas pertinentes para evitar el accidente en el cual participó y que se originó en la maniobra de adelantamiento que efectuó de manera extremadamente imprudente (...). Tercero: Que la experiencia adquirida debió conducir al demandante a prever la envergadura de sus actuaciones y en consecuencia, a tomar las medidas pertinentes con mayor rigor que un conductor particular, en tanto, por su oficio o profesión, la sujeción a éstas es ineludible y consustancial al cumplimiento de su contrato de trabajo [...]".

${ }^{29}$ Véase sentencia de la Corte de Apelaciones de Santiago de 16 de abril de 1998, en Gaceta Jurídica, 214 (1998), p. 188: "La imprudencia temeraria, a que alude el artículo $160 \mathrm{~N}^{\circ}$ 5CT., debe ser grave [...]”; y sentencia de la Corte Suprema de 27 de agosto de 2007 (causa ingreso corte $\mathrm{N}^{\circ}$ 3916-2006, en www.poderjudicial.cl): "[...] la conducta u omisión que se requiere para la configuración de la causal que se examina consiste en un comportamiento negligente o imprudente de cierta entidad, que sea capaz de producir los efectos que la misma norma contempla, como son la afectación de la seguridad de la empresa o de los trabajadores o la salud de éstos; sin que sea necesario la existencia de un dolo o intención especial'. En el plano doctrinario, véase también Goerlich Peset, José María, Particularidades de la responsabilidad indemnizatoria del trabajador por los daños causados a la empresa en el desarrollo de la prestación laboral: un intento de explicación, en Revista Española de Derecho del Trabajo, 152 (2011), pp. 959 ss. 
Así ocurriría, por ejemplo, cuando el comportamiento es ajeno al i t e r c o n t r a c t u a l, o bien, no se encuentra permitido por el Derecho; pero, por el contrario, la conducta estaría justificada si con ello se pretendía remediar un mal mayor al resultado que se causó. Desde esta perspectiva, el te s t d e g r a ved a d permite calificar la entidad del acto, omisión o imprudencia, estructurando los límites de la conducta reprochada ${ }^{30}$. El test de culpabilidad, por su parte, permite determinar si el hecho imputado como infraccional alcanza el estándar de justificación ${ }^{31}$.

\section{El nexo causal consistente en la afectación.}

El Código del Trabajo no exige un resultado perjudicial para aceptar la causal. Sólo se limita a señalar que el comportamiento del trabajador debe traer aparejada una alteración mínima, una a f e c t a c i ó n, de ciertos bienes jurídicos que el mismo precepto se encarga de señalar ${ }^{32}$. En este orden de ideas, y a diferencia de lo que ocurre con otras causales (v. gr., artículo $160 \mathrm{~N}^{\circ} 6 \mathrm{CT}$.), lo que exige en este caso el Código es que exista un resultado tendiente a afectar o menoscabar el funcionamiento de la empresa o la salud de los trabajadores; pero ello no implica que deba producirse necesariamente un resultado positivo de p e r j u i c i o.

Consecuente con lo anterior, para una parte de la jurisprudencia el vocablo a f e c t a r no puede ser visto en principio como un sinónimo de producción cierta de un daño, "sino sólo como la posibilidad concreta de que ese perjuicio se produzca, atendido que en el caso en que lo amenazado sea la salud de otros dependientes la disposición del artículo 184 del Código del ramo prevé la obligación esencial del empleador de adoptar todas las medidas

${ }^{30}$ A nivel jurisprudencial, véase: sentencia de la Corte de Apelaciones de Santiago de 25 de mayo de 1994, en Gaceta Jurídica, 172 (1994), p. 127.

${ }^{31}$ Véase: Montoya Melgar, Alfredo, Derecho del trabajo, cit. (n. 28), pp. 468469.

${ }^{32}$ Véase la sentencia de la Corte Suprema de 23 de mayo de 2013 (causa ingreso corte No 292-2013, en www.poderjudicial.cl): “(Los actos, omisiones o imprudencia del trabajador) Deberán, además, afectar a los bienes jurídicos establecidos en la norma referida, expresión que no puede entenderse como sinónimo de producción cierta de un daño, sino sólo como la posibilidad concreta de que ese perjuicio se produzca". Véase también sentencia de la Corte de Apelaciones de Concepción de 17 de diciembre de 2014 (causa ingreso corte No 326-2014, en www.poderjudicial.cl). 
necesarias para proteger eficazmente la vida y salud de los dependientes"33. El mismo criterio ha planteado parte de la doctrina ${ }^{34}$.

De esta manera, el uso del vocablo a f e c $\mathrm{t}$ a $\mathrm{r}$ deja al descubierto que para invocar la causal no se requiere la ocurrencia de un d a ñ o específico. Tampoco es preciso que el actuar del trabajador tenga como consecuencia un determinado p e r j u i c i o. Por el contrario, todo indica que el estándar exigido por la norma es simplemente que el comportamiento reprochado acarree una alteración o mudanza en los bienes del establecimiento, en su funcionamiento u organización, así como en la salud o seguridad de los trabajadores ${ }^{35}$.

\section{Los bienes jurídicos protegidos.}

a) La seguridad o el funcionamiento del establecimiento. El primer bien jurídico protegido por el artículo $160 \mathrm{~N}^{\circ} 5$ CT. es la seguridad o el funcionamiento del establecimiento (y no de la empresa). En efecto, la norma centra su protección en los mecanismos que aseguran la

${ }^{33}$ Véase la sentencia de la Corte Suprema de 23 de mayo de 2013 (causa ingreso corte $\mathrm{N}^{\circ} 292-2013$, en www.poderjudicial.cl). En igual sentido, sentencia de la Corte Suprema de 28 de abril de 2005, en Gaceta Jurídica, 298 (2005), p. 254: " $L a$ expresión 'afectar' no puede entenderse como sinónimo de producción cierta de un daño, sino sólo como la posibilidad cierta de que ese perjuicio se produzca". La misma argumentación se esgrime en la sentencia de la Corte Suprema de 28 de abril de 2005, en Gaceta Jurídica, 298 (2005), p. 254; de 14 de julio de 2010 (causa ingreso corte $\mathrm{N}^{\circ}$ 1606-2010, en www.poderjudicial.cl); y en la sentencia de la Corte Suprema de 8 de agosto de 2012, en Revista Fallos del Mes, 558 (2012), pp. 647 ss.

${ }^{34}$ Véase: en el ámbito comparado, Cabanellas, Guillermo, Tratado de derecho laboral, cit. (n. 15), p. 190: "A nuestro juicio, procede el despido cuando ha habido negligencia por parte del trabajador, aun cuando la misma no le haya producido a la empresa daños reales y efectivos".

${ }^{35}$ Una posición algo distinta puede consultarse en el fallo de la Corte de Apelaciones de Valparaíso de 2 de abril de 2015 (causa ingreso corte No 85-2015, en www.poderjudicial.cl), según el cual: "los actos, omisiones o imprudencias temerarias a que alude el art. $160 \mathrm{~N}^{\circ} 5 \mathrm{CT}$. deben afectar real y efectivamente a la seguridad o al funcionamiento del establecimiento o la seguridad o actividad de los trabajadores o su salud, lo que no ha sido acreditado. La disposición exige 'que afecten' y no 'que puedan afectar'. Esta diferencia no es solo semántica, pues implica que el daño es parte de los elementos que tipifican la causal, por lo que el juez debe ponderar la entidad de ese daño $y$, sobre esa base, determinar si la imprudencia fue temeraria o no". La parte final de esta sentencia termina asimilando el verbo a f e $\mathrm{c} t \mathrm{a} r$ con la producción cierta de un d a ñ o, cuestión que en rigor no está dentro de la estructura de la causal. Lo que exige el Código, en definitiva, es una alteración y no necesariamente la producción cierta de un daño. En el plano doctrinario, véase, además, García MurCia, Joaquín, Responsabilidades y sanciones en materia de seguridad y salud en el trabajo (Pamplona, Aranzadi, 1998), p. 62. 
normal actividad del establecimiento a objeto de que éstos no fallen, no se frustren o violenten. De esta manera, la norma busca asegurar que el establecimiento quede libre y exento de todo peligro, daño o riesgo. Tal como está redactada la causal, pareciera que ella se enfoca en el establecimiento en su conjunto así como en los aparatos, utensilios o maquinarias que forman parte del mismo.

En cuanto al f u n c i o n a m i e n t o, la causal pretende resguardar que las actividades o funciones propias del establecimiento no se vean afectadas por un determinado acto, omisión o imprudencia temeraria del trabajador ${ }^{36}$. Cualquier alteración, injustificada y de cierta entidad y gravedad, que impida el ejercicio de las funciones regulares de la unidad productiva, queda incorporada dentro del núcleo definitorio de la infracción ${ }^{37}$. Con todo, hay que tener presente que la ley no circunscribe la alteración del funcionamiento a la mera actividad normal, periódica o habitual del establecimiento. Por el contrario, al no calificar el tipo de funcionamiento afectado la norma deja abierta las alternativas en cuya virtud también podría perseguirse la responsabilidad laboral del trabajador cuando su conducta altera por ejemplo un evento extraordinario de la unidad productiva.

Como se ha dicho, el artículo $160 \mathrm{~N}^{\circ} 5 \mathrm{CT}$. centra el resguardo en la figura del establecimiento y no de la organización empresarial. La idea jurídico-laboral de empresa se ha venido manifestando en la práctica como un concepto general y abstracto que presupone la existencia de una organización. Dicha organización ha derivado, en la actualidad, en una variedad infinita de vertebraciones internas, en la cual destacan unidades organizativas de reducidas dimensiones y de gran flexibilidad, pero que no alcanzan la condición de ente unitario ${ }^{38}$.

A pesar de lo anterior, no cabe duda de que la explicación concreta de

${ }^{36}$ Así lo resolvió en su momento la sentencia de reemplazo de la Corte Suprema de 27 de agosto de 2007 (causa ingreso corte $N^{\circ}$ 3916-2006, en www.poderjudicial. cl), toda vez que "la conducta desarrollada por la actora, en circunstancias que cumplía labores de auxiliar paramédico consistente en haber alterado la composición de solución de formalina, empleada en la esterilización del material reutilizado por pacientes que concurrian a tal centro a efectuar procedimientos de diálisis, al no respetar las indicaciones respecto de su preparación dadas por la empleadora y fijadas, incluso por la autoridad de salud, constituye un acto de tal entidad y gravedad, que han afectado la seguridad y funcionamiento del establecimiento de la demandada, atendida la naturaleza de los servicios que ésta presta, lo que permite justificar el despido de la trabajadora".

${ }^{37}$ Véase sentencia de la Corte Suprema de 25 de mayo de 2004 (causa ingreso corte 2092-2003, en www.poderjudicial.cl).

${ }^{38}$ Véase, por todos: IruReta URIarte, Pedro, Empresa y personalidad jurídica, en Revista Persona y Sociedad, 26 (2002) 1, p. 2099. 
la organización empresarial se verifica en el denominado e $\mathrm{s}$ a b l e c i $\mathrm{m}$ i e n to o, en palabras del derecho comparado, en el c e n tro de $\mathrm{t} \mathrm{r}$ a b a j o ${ }^{39}$. En efecto, y aun cuando el Código del Trabajo chileno utiliza de manera reiterada la palabra e $s \mathrm{tab} \mathrm{l}$ e $\mathrm{c}$ i m i e $\mathrm{n} \mathrm{t} \mathrm{o}^{40}$, lo cierto es que doctrinariamente, y por influencia del Derecho alemán, la expresión c e n $\mathrm{tro} \mathrm{de} \operatorname{trabaj}$ o ha terminado desplazando cualquier otra pretensión lingüística como podrían ser la de e $\mathrm{sta}$ b l e c i m i e $\mathrm{n}$ to, in d u s $\mathrm{tr}$ i a o n e g o c i o. Esta opción terminológica se justifica, entre otros factores, por las dificultades que han existido para separar las nociones de empresa, establecimiento y empleador, como si se tratara de expresiones similares ${ }^{41}$. Así ocurre, por ejemplo, con el artículo 47 CT., el cual termina asimilando para efectos de gratificación los conceptos de empresa y establecimiento.

Con esto se quiere demostrar que el centro de trabajo no constituye, ni con mucho, un concepto $\mathrm{l} \mathrm{a} \mathrm{b}$ o r a l i z a d o del establecimiento mercantil ${ }^{42}$, ya que este último término tiene una innegable connotación locativa que resulta demasiado restrictiva para el Derecho del Trabajo. De esta forma, la referencia al e s t a b l e c i m i e n t o, tan propia de nuestro Código, ha sido dejada de lado en el ámbito dogmático y en el Derecho comparado en razón del innegable significado geográfico que dicha expresión alcanza en la disciplina comercial.

Con todo, y más allá de las denominaciones lingüísticas, lo cierto es que la expresión utilizada en el artículo 160 No 5 CT. busca reflejar la idea del "Be-

${ }^{39}$ Véase, por ejemplo, el artículo 1.5 del Estatuto de los Trabajadores español, que concibe al centro de trabajo como una "unidad productiva con organización especifica, que sea dada de alta, como tal, ante la autoridad laboral'. En el entorno latinoamericano, véase también el artículo $2^{\circ}$ de la Ley No 19.587 , sobre higiene y seguridad en el trabajo, de Argentina: "A los efectos de la presente ley los términos 'establecimiento', 'explotación', 'centro de trabajo' o 'puesto de trabajo' designan todo lugar destinado a la realización o donde se realicen tareas de cualquier indole o naturaleza con la presencia permanente, circunstancial, transitoria o eventual de personas fisicas y a los depósitos y dependencias anexas de todo tipo en que las mismas deban permanecer o a los que asistan o concurran por el hecho o en ocasión del trabajo o con el consentimiento expreso o tácito del principal. (...)".

${ }^{40}$ Por ejemplo, en los artículos 9, 12, 15, 18, 22, 29, 38, 47, 58, 64, 74, 75, 76, 153, 154, 161, 183-Ñ , 190, 193, 194, 197, 203, ó 204, por mencionar sólo preceptos de derecho individual.

${ }^{41}$ Véanse: Thayer Arteaga, William - Novoa Fuenzalida, Patricio, Manual de derecho del trabajo, cit. (n. 10), p. 146.

${ }^{42}$ Véase: GonZÁlez Biedma, Eduardo, El cambio de titularidad de la empresa en el derecho del Trabajo (Madrid, Centro de Publicaciones Ministerio del Trabajo y Seguridad Social, 1989), p. 103; y Monereo Pérez, José Luis, Las relaciones de trabajo en la transmisión de la empresa (Madrid, Servicio de Publicaciones Ministerio de Trabajo y Seguridad Social, 1987), p. 235. 
trieb" del derecho alemán: una u n i d a d té c n i c a - o r g a n i z a d a cuyo fin específico es la consecución de obj e t i v o s i n m ed i a t o ${ }^{43}$. En este orden de ideas, el centro de trabajo (o establecimiento, en palabras de nuestro Código) corresponde en términos generales a la concreción específica del ejercicio de las relaciones laborales, y su condición de unidad básica refleja de modo efectivo y directo la prestación laboral. Esta especificidad es de tal relevancia que permite diferenciar la idea jurídica del centro de trabajo (o establecimiento) de una noción puramente socioeconómica de la organización ${ }^{44}$. El centro de trabajo (o establecimiento), por tanto, no es la empresa propiamente tal, pero ciertamente presupone la existencia de ésta ${ }^{45}$. Más bien, se trata de la unidad técnico-productiva donde se plasman los derechos y obligaciones de cada parte contratante, especificando la actividad de cada cual, cuestión que lo convierte en un centro de imputación de relaciones jurídico-laborales organizadas ${ }^{46}$.

Desde esta perspectiva, el centro de trabajo no puede ser confundido como una especie de sinónimo de empresa. Tampoco puede ser configurado de manera rígida o restrictiva; por el contrario, existen caracteres abiertos que facilitan su autonomía y flexibilidad. Es, en definitiva, un concepto funcional a los fines de aplicación de las normas laborales ${ }^{47}$.

Esta opción pareciera llevar a la tesis de que los sujetos que se hayan vinculados laboralmente terminan relacionándose no tanto en el ámbito de una e $\mathrm{m}$ p r e $s$ a, en sentido abstracto, sino con la unidad productiva en la cual se prestan los servicios; ya que es allí donde, en definitiva, se plasmará el

${ }^{43}$ Véase: Miñambres Puig, César, El centro de trabajo (Madrid, Servicio de Publicaciones Ministerio de Trabajo y Seguridad Social, 1985), p. 63. Véase: también, Cristóbal Roncero, Ma. del Rosario, Los derechos de los trabajadores en la transmisión de empresas. Estudio del ordenamiento jurídico alemán (Madrid, Servicio de Publicaciones Facultad de Derecho, Universidad Complutense de Madrid, 1999), pp. 58 ss.

${ }^{44}$ Véase: Sala Franco, Tomás - Ramírez Martínez, Juan Manuel, El concepto de centro de trabajo, en Actualidad Laboral, 33 (1985), p. 1653.

${ }^{45}$ Las mismas normas del Código del Trabajo dejan en evidencia esta contraposición. Véanse, por ejemplo y entre otras, los artículos 12, 74, 74, 153, 154 No 9, 302, 315, 376 y 384, en que las nociones de empresa y establecimiento se plantean como alternativas diversas. En el plano doctrinal, véase también RUPRECHT, Alfredo J., Concepto de empresa, establecimiento y explotación, en Revista del Instituto de Derecho del Trabajo e Investigaciones Sociales, 10, 18 (1974), p. 7.

${ }^{46}$ Véase: Monereo Pérez, José Luis, Teoría jurídica de los grupos de empresas y derecho del trabajo (Granada, Comares, 1997), p. 34; y del mismo autor, La transmisión parcial de empresa: el "centro de trabajo" y la "unidad productiva autónoma" de la empresa, en Documentación Laboral, 52 (1997), pp. 62-63 y 68.

${ }^{47}$ Véase: Monereo Pérez, José Luis, La transmisión parcial de empresa, cit. (n. 45), pp. 64-65. 
mayor número de relaciones individuales y colectivas de trabajo. Lo relevante, no obstante, es que la idea de centro de trabajo es inherente a la noción de organización es pecífic a y a u tón o ma ${ }^{48}$, cuestión que no implica, por cierto, una absoluta autonomía de organización, toda vez que el centro se integra necesariamente en un contexto mayor que es la empresa $^{49}$. Y esta última, aparece representada como una unidad organizativa, y no como una mera unidad técnica de producción ${ }^{50}$.

La construcción dogmática de centro de trabajo consta, en lo substantivo, de dos elementos: i) El primero de ellos, se refiere al hecho de que para hablar de centro de trabajo debemos estar en presencia de una unidad productiva; y $i$ Lo segundo, es que esta unidad productiva debe contar con una organización específica. Es decir, debe estar organizada independientemente del conjunto empresarial en que se integra ${ }^{51}$. Estos elementos son de naturaleza eminentemente material o substantiva, aun cuando habrá que reconocer que su regulación legal supondrá partir de la base de que se trata de conceptos jurídicamente indeterminados ${ }^{52}$.

Cuando se hace referencia a la unidad productiva, existen dos interpretaciones frente al alcance que ésta tiene dentro de la configuración empresarial. Una de ellas, de naturaleza restrictiva, la identifica como un lugar físico donde los trabajadores pueden llevar a cabo la actividad económica principal y total de la empresa. En este contexto, habría un centro de trabajo allá donde se produjeran bienes o servicios terminados, aptos para la venta y consumo, y

${ }^{48}$ Véase: Ramírez Martínez, Juan Manuel - Sala Franco, Tomás, El centro de trabajo: configuración legal, en BorRajo DACRUZ, Efrén (director), Comentarios a las Leyes Laborales. El Estatuto de los Trabajadores (Edersa, Madrid, 1985), I, p. 236. Véase también: GONZÁlez Biedma, Eduardo, El cambio de titularidad de la empresa, cit. (n. 41), p. 101; Monereo Pérez, José Luis, La transmisión parcial de empresa, cit. (n. 45), p. 63; y del mismo autor, Teoría jurídica de los grupos de empresas, cit. (n. 45), pp. 27, 34 y 40. En el plano de la jurisprudencia administrativa, véase, además, Dictamen No 0348/10, de 19 de enero de 1995, de la Dirección del Trabajo, el cual hace referencia al establecimiento como una individualidad de la empresa que se encuentra afecta a una finalidad intermedia o final dentro de la misma, y que por el grado de autonomía funcional y administrativa que presenta, toma una singularidad distinta de la empresa

${ }^{49}$ Véase: Miñambres Puig, César, El centro de trabajo, cit. (n. 42), p. 130; y MoNEREO PÉrEZ, José Luis, La transmisión parcial de empresa, cit. (n. 45), p. 66.

${ }^{50}$ Véase: Rivero LAMAS, Juan, Limitación de los poderes empresariales y democracia industrial (Zaragoza, Secretariado de Publicaciones, Universidad de Zaragoza, 1986), p. 25.

${ }^{51}$ Véase: Monereo PéRez, José Luis, Las relaciones de trabajo, cit. (n. 41), p. 229; y del mismo autor, Teoría jurídica de los grupos de empresas, cit. (n. 45), p. 40.

${ }^{52}$ Véase: Monereo Pérez, José Luis, La transmisión parcial de empresa, cit. (n. 45), p. 61. 
no donde se realice una actividad parcial que necesitará de una manipulación $o$ actividad posterior a realizar en otro lugar ${ }^{53}$. Pero esta alternativa no parece totalmente congruente con la idea jurídico-laboral del centro de trabajo, ya que esta expresión tiene un contenido jurídico propio y específico que no necesariamente coincidirá con el l u ga r d e trabajo. Prueba de ello lo dan el contrato a domicilio, los centros móviles e itinerantes ${ }^{54}$, o las organizaciones empresariales de carácter horizontal ${ }^{55}$.

Una segunda interpretación ve en el término u $\mathrm{n}$ i d a d p r o d u c t i v a a una entidad técnica de producción, que se diferenciaría de la unidad económica productiva que sería la empresa propiamente tal. De esta forma, la empresa sería un todo que admite dentro de sí una serie de partes que actuarían como centros de trabajo (o establecimiento) ${ }^{56}$. Esta segunda alternativa adquiere mayor significación desde una perspectiva estrictamente laboral, ya que nada impide que la unidad productiva ostente varias dependencias donde se plasme el ejercicio de la prestación de trabajo ${ }^{57}$. Lo distintivo del "Betrieb", por tanto, es su expresión organizativa, sin perjuicio del aporte indiciario que supondrá el dato geográfico. Dicha expresión permite configurar un orden creado y orientado al logro de un determinado objetivo. ${ }^{58} \mathrm{Y}$ es ese el significado que debiera otorgársele a la figura del establecimiento que, con cierta espontaneidad, utiliza nuestro Código del Trabajo y que ciertamente está presente en la regulación de su artículo $160 \mathrm{~N}^{\circ} 5$.

b) La actividad de los trabajadores. Otro de los efectos que exige la causal del artículo $160 \mathrm{~N}^{\circ} 5 \mathrm{CT}$. es que los actos, omisiones o imprudencias temerarias afecten la a c t i v i d a d de los trabajadores. Como se puede apreciar, el acento está colocado en el obrar del prestador del servicio (el

${ }^{53}$ Véase: Ramirez Martínez, Juan Manuel - Sala Franco, Tomás, El centro de trabajo, cit. (n. 47), p. 233; y de los mismos autores, El concepto de centro de trabajo, cit. (n. 43), p. 1651.

${ }^{54}$ Véase: en esta línea, Dictamen No 1217/059, de la Dirección del Trabajo, según el cual los aviones comerciales de pasajeros son establecimientos de empresa, o parte de éstos en caso que se trate de varios aviones pertenecientes a una misma flota.

${ }^{55}$ Véase: MiÑAmbres Puig, César, El centro de trabajo, cit. (n. 42), pp. 186, 188 y 190. Véase: también, González Biedma, Eduardo, El cambio de titularidad de la empresa, cit. (n. 41), p. 102; Monereo Pérez, José Luis, Teoría jurídica de los grupos de empresas, cit. (n. 45), p. 37; y del mismo autor, La transmisión parcial de empresa, cit. (n. 45), p. 65.

${ }^{56}$ Véase: Miñambres Puig, César, El centro de trabajo, cit. (n. 42), pp. 163 y ss; y Sala Franco, Tomás, y Ramírez Martínez, Juan Manuel, El concepto de centro de trabajo, cit. (n. 43), pp. 1651 y ss.

${ }^{57}$ Véase: Miñambres Puig, César, El centro de trabajo, cit. (n. 42), p. 192.

${ }^{58}$ Véase: Monereo Pérez, José Luis, Teoría jurídica de los grupos de empresas, cit. (n. 45), p. 42. 
trabajador), y no en las operaciones de su empleador. De esta manera, el Código sitúa la consecuencia en una perturbación relevante en las tareas normales del trabajador y de los compañeros de labores del infractor que prestan servicios en la empresa.

El término "a c tivi d a d" nos reconduce al conjunto de operaciones o tareas propias que llevan a cabo los trabajadores de la respectiva organización. Y esas tareas $\mathrm{u}$ operaciones se encuentran íntimamente conectadas con el contenido obligacional del respectivo cargo o función pactado en el contrato. Desde esta perspectiva, lo que el Código quiere evitar es que la conducta reprochada afecte la diligencia o eficacia normal que un trabajador debe realizar en virtud de su contrato de trabajo. Ello supone dejar fuera de este capítulo de la hipótesis extintiva aquellos actos, omisiones o imprudencias ajenos a las tareas normales del trabajador; así como también cualquier afectación que se produjera fuera del ámbito propiamente laboral.

El estándar de afectación que exige la causal es aquél que normalmente cabría exigirle al trabajador o a su compañero de labores en el desempeño de sus funciones regulares. Pero como el requisito de la gravedad se encuentra inserto en todo el diseño del artículo $160 \mathrm{~N}^{\circ} 5 \mathrm{CT}$., esa afectación debe ser cualitativamente relevante, de una cierta entidad que permita concluir que los actos, omisiones o imprudencias efectivamente alteraron de modo significativo la ejecución de las tareas del personal de la empresa.

En cuanto a la extensión de las personas afectadas, el Código nada dice si la afectación debe cubrir a una cantidad significativa de trabajadores de la empresa, o por el contrario basta con que ella se refiera a un trabajador en particular. En general, la jurisprudencia no ha tenido mayor inconveniente en aplicar la causal cuando la afectación se refiera a un solo trabajador. Así lo hizo, por ejemplo, cuando el infractor dañó la salud de un compañero ${ }^{59}$ o le hizo una broma que terminó provocando un accidente laboral ${ }^{60}$. Por tanto, no existe a p r i o r i una limitación al momento de calificar la conducta que se vincule con el número de personas afectadas. Tampoco la jurisprudencia ha tenido inconveniente para configurar la causal en aquellos supuestos que el propio trabajador reúne simultáneamente las cualidades de sujeto activo y pasivo de la infracción ${ }^{61}$.

${ }^{59}$ Véase: sentencia de la Corte Suprema de 23 de mayo de 2013 (causa ingreso corte $\mathrm{N}^{\circ}$ 292-2013, en www.poderjudicial.cl).

${ }^{60}$ Véase: sentencia de la Corte Suprema de 14 de marzo de 2006 (causa ingreso corte $\mathrm{N}^{\circ}$ 6658-2006, en www.poderjudicial.cl).

${ }^{61}$ Véase: por ejemplo, la sentencia de la Corte de Apelaciones de Concepción de 17 de diciembre de 2014 (causa ingreso corte No 326-2014, en www.poderjudicial. cl). En dicha causa, se concluyó que concurría la causal "por cuanto además de la 
Con todo, no cabe duda que la evaluación del comportamiento eventualmente infraccional estará sujeto a los niveles de gravedad que se observen en cada caso en particular. Los criterios que forman parte de la conocida teoría gradualista y personalizadora debieran permitir resolver adecuadamente los alcances que presenta la causal dependiendo de si el hecho reprochado afecta a varios trabajadores o a uno sólo de los compañeros de tareas ${ }^{62}$.

De lo que no cabe duda, es que el Código circunscribe el ilícito al hecho de que se afecte la actividad de los trabajadores. Por tanto, el sujeto pasivo de la infracción es el trabajador persona natural y no la persona del empleador. Habrá otras causales que amparen la actividad de este último, ya que el propio artículo $160 \mathrm{~N}^{\circ} 5 \mathrm{CT}$. no ha incorporado como bienes protegidos ni la salud del empleador ni la actividad misma que éste realiza (sin perjuicio del amparo que se otorga a la seguridad y funcionamiento del establecimiento).

Por último, el término $\mathrm{t} \mathrm{ra} \mathrm{b}$ a j a d o $\mathrm{r}$ obliga a determinar quiénes son exactamente los sujetos pasivos de la conducta reprochada. Ya se ha dicho que la causal no hace referencia el empleador propiamente tal. Tampoco quedarían cubiertos como sujetos pasivos de esta hipótesis extintiva los familiares de éste, sus clientes o terceras personas que se relacionaran con la actividad productiva en calidad de proveedores o de prestadores independientes. Por el contrario, el término trabajador debe asociarse a la idea de un dependiente laboral del mismo empleador, más aún si se considera que este tipo de causales busca, entre otras cosas, cautelar la disciplina mínima que debe imperar para desarrollar las tareas o actividades que les corresponden a todos los trabajadores de la empresa. Este mismo fundamento obliga a concluir que dentro del término "trabajador" también caben aquellas personas que prestan servicios dentro del ámbito

natural valoración que cualquier persona pudiese hacer de una escalada a esa altura y en esas condiciones es un acto de riesgo, más aún en el caso de los demandados quienes han recibido charlas, participado en cursos y capacitaciones por lo que no podian menos que saber las consecuencias técnicas de conducta en los términos antes indicados [...]". En sentido similar, véase sentencia de la Corte de Apelaciones de Talca de 29 de julio de 2014 (causa ingreso corte No 100-2014, en www.poderjudicial.cl): "Segundo: Que de la lectura de la sentencia recurrida queda en evidencia que [...] en el lugar donde se almacena armamento y municiones el actor fue sorprendido fumando como también la falta de utilización del chaleco antibalas, hechos ambos que fundamentaron el despido [...]".

${ }^{62}$ Véase: por todas, sentencia de la Corte Suprema de 31 de diciembre de 2008, en Revista Fallos del Mes, 550 (2008), p. 375. A nivel doctrinario véase además, Ortiz Lallana, M. Carmen, Causas y formas del despido disciplinario (en torno a los artículos 54 y 55). El Estatuto de los Trabajadores veinte años después, en Revista Española de Derecho del Trabajo, 100, I (2000), p. 1123. 
organizativo de la empresa en calidad de trabajadores subcontratados o de servicios transitorios. Sin lugar a dudas, ellos también tienen la calidad jurídica de trabajador y mantienen un vínculo normativamente regulado con el empleador del eventual infractor. La alteración en la actividad de otras personas vinculadas comercial o civilmente con el empleador, debieran ser reconducidas a causales más genéricas, como la falta de probidad (art. $160 \mathrm{~N}^{\circ} 1$ CT.) o el incumplimiento grave de las obligaciones (art. $160 \mathrm{~N}^{\circ} 7$ CT.).

c) La seguridad y la salud de los trabajadores. La últimas dos figuras protegidas por el artículo $160 \mathrm{~N}^{\circ} 5 \mathrm{CT}$. son la seguridad y la salud de los trabajadores. Se trata de bienes jurídicos diferenciados, pero cuya finalidad es precisamente la indemnidad del trabajador ${ }^{63}$.

Como es ampliamente sabido, en materia de seguridad y salud en el trabajo, lo normal es que los deberes de protección corran por cuenta del empleador ${ }^{64}$. En el diseño clásico, él es un deudor de seguridad y está obligado a impetrar las medidas necesarias que resguarden la integridad física y síquica del trabajador, quien se comporta a estos efectos como un beneficiario ${ }^{65}$. Esta obligación impone sobre el empleador una diligencia mínima, más aún si se considera que él se encuentra en una mejor disposición para proteger la seguridad y salud al interior de la empresa ${ }^{66}$.

No obstante lo anterior, en el sistema normativo protector de la seguridad y salud en el trabajo se interconectan garantías y responsabilidades capaces de armonizar derechos y deberes de ambas partes ${ }^{67}$. Estas

${ }^{63}$ Véase: Barrientos Zamorano, Marcelo, La obligación de seguridad en la subcontratación laboral: previsibilidad del hecho y del daño, en Revista Chilena de Derecho, 39, 1 (2012), p. 87

${ }^{64}$ Véase: por todos, García Murcia, Responsabilidades y sanciones, cit. (n. 35), pp. 43 y ss.

${ }^{65}$ Véase: Montoya Melgar, Alfredo, Los deberes del trabajador en materia de seguridad en el trabajo y la sanción de su incumplimiento, en GÁRATE CASTRO, Javier (coordinador), Cuestiones actuales sobre el despido disciplinario (Santiago de Compostela, Universidad de Santiago de Compostela, 1997), p. 51. Véase también García MuRCIA, Joaquín, Los incumplimientos del trabajador en materia de seguridad y salud en el trabajo como causa de despido disciplinario, en GÁRATE CASTRO, Javier (coordinador), Cuestiones actuales sobre el despido disciplinario (Santiago de Compostela, Universidad de Santiago de Compostela, 1997), p. 58.

${ }^{66}$ Véase: Martin Hernández, María Luisa, Los deberes de los trabajadores en materia de seguridad y salud en el trabajo: aspectos materiales y procesales, en Estudios Jurídicos (2006), p. 3. El texto por el que se cita, fue facilitado por la autora dada las dificultades para acceder al original.

${ }^{67}$ Véase: CANO GaLÁN, Yolanda, La formación en prevención de riesgos laborales: su configuración como deber de los trabajadores, en Revista del Ministerio de Trabajo y Asuntos Sociales, 53 (2004), p. 207. Véase también: GonZÁlez OrTEga, Santiago, 
garantías y responsabilidades no son homogéneas ni tampoco responden a un principio de reciprocidad de las prestaciones, pero sí reflejan medios instrumentales indispensables para alcanzar los objetivos de seguridad y salud que ha diseñado el ordenamiento legal ${ }^{68}$.

En materia de seguridad y salud, el trabajador asume básicamente tres tipos de obligaciones: de autoprotección, de cumplimiento de las medidas de protección y de cooperación con el empleador ${ }^{69}$. En este último estadio, el trabajador se configura no sólo como sujeto beneficiario sino que también, y al mismo tiempo, como sujeto obligado al cumplimiento de los deberes de seguridad y salud en el trabajo ${ }^{70}$. Dichas obligaciones son auténticos deberes jurídicos, de carácter complementario a su obligación principal que es la de prestar servicios, y tienen por objeto que el trabajador cumpla con las normas y procedimientos de trabajo seguro, las cuales se encuentran contenidas entre otros instrumentos en normas legales y reglamentarias, en el reglamento interno de la empresa ${ }^{71}$ y en las directrices impartidas por el Comité Paritario de Higiene y Seguridad ${ }^{72}$.

Seguridady salud en el trabajo (en torno al artículo 19), en Revista Española de Derecho del Trabajo, 100 (2000) 1, pp. 555 ss.

${ }^{68}$ Véase: Martin Hernández, María Luisa, Los deberes de los trabajadores, cit. (n. 64), p. 7. Véase: además, NúNEzZ GonZÁLez, Cayetano, Prevención de riesgos laborales en Chile (2a edición, Santiago, Librotecnia, 2014), p. 120.

${ }^{69}$ Véase: Martin Hernández, María Luisa, Los deberes de los trabajadores, cit. (n. 64), p. 29.

${ }^{70}$ De allí que se haya sostenido que: "actúa culposamente un trabajador si no realiza un uso correcto, utiliza el medio de seguridad para fines inesperados e impropios del bien o les da un destino inadecuado o simplemente no los utiliza", por Barrientos Zamorano, Marcelo, La obligación de seguridad en la subcontratación laboral, cit. (n. 62), p. 101.

${ }^{71} \mathrm{El}$ artículo $153 \mathrm{CT}$. indica que una de las finalidades del Reglamento Interno es precisamente la de establecer "las obligaciones y prohibiciones a que deban sujetarse los trabajadores, en relación con sus labores, permanencia y vida en las dependencias de la respectiva empresa o establecimiento" (cuestión que se reafirma en el artículo $154 \mathrm{~N}^{\circ} 5$ y 10 CT.). Asimismo, el artículo 67 de la Ley $\mathrm{N}^{\circ} 16.744$ es perentorio al señalar que las empresas estarán obligadas a mantener al día los reglamentos internos de higiene $y$ seguridad en el trabajo " $y$ los trabajadores a cumplir con las exigencias que dichos reglamentos les impongan. Los reglamentos deberán consultar la aplicación de multas a los trabajadores que no utilicen los elementos de protección personal que se les haya proporcionado o que no cumplan las obligaciones que les impongan las normas, reglamentaciones $o$ instrucciones sobre higiene y seguridad en el trabajo".

${ }^{72}$ Por ejemplo y entre otros: el Decreto Supremo No 594, de 2000, del Ministerio de Salud, establece una serie de deberes en relación con el trabajador: $i$ ) "Se prohibe a los trabajadores cuya labor se ejecuta cerca de maquinarias en movimiento y órganos de transmisión, el uso de ropa suelta, cabello largo y suelto, y adornos susceptibles de ser atrapados por las partes móviles" (artículo 40); ii) Para conducir maquinarias automo- 
Por lo tanto, el trabajador asume un deber jurídico individual de velar tanto por su propia seguridad y salud, como por la de las demás personas a las que pueda afectar su actividad ${ }^{73}$.

Sin perjuicio de lo anterior, las exigencias de protección de la seguridad y salud que pesan sobre el trabajador deben ser evaluadas según la formación de éste, de acuerdo a sus posibilidades y teniendo en cuenta las instrucciones que el propio empleador ha impartido ${ }^{74}$. Asimismo, deberá considerarse el cargo o función que éste desempeña en la empresa, así como el contenido obligacional que a éste le corresponde dentro de la organización $^{75}$. A fin de cuentas, los deberes que en esta materia debe asumir el trabajador no lo convierten en el principal responsable de la protección frente a los riesgos laborales, cuestión que el ordenamiento jurídico centra fundamentalmente en el empleador ${ }^{76}$.

Como se puede observar, los deberes de seguridad y protección de la salud no son iguales para el empleador en comparación con un trabajador. En el primer caso, el ordenamiento jurídico le exige al empleador un deber básico de diligencia; al trabajador, en cambio, el artículo $160 \mathrm{~N}^{\circ} 5 \mathrm{CT}$. le exige un deber mínimo consistente en que no incurra, a lo menos, en imprudencias temerarias. Esta distinción deja en evidencia el estándar de cumplimiento que para una u otra parte del contrato de trabajo exige el ordenamiento laboral. Pero la diferencia que marca esta causal no sólo se

trices en los lugares de trabajo, "los trabajadores deberán poseer la licencia de conductor que exige la Ley de Tránsito” (artículo 43); iii) El trabajador tiene la obligación de usar los elementos de protección personal en forma permanente mientras se encuentre expuesto a un riesgo dentro de la empresa (artículo 53); y iv) En ningún caso, el trabajador podrá "consumir sus alimentos al mismo tiempo que ejecuta labores propias del trabajo" (artículo 128). Por otra parte, el artículo 66 de la Ley $\mathrm{N}^{\circ} 16.744$ señala dentro de las funciones de los Comités Paritarios de Higiene y Seguridad el "asesorar e instruir a los trabajadores para la correcta utilización de los instrumentos de protección" (art. $\left.66 N^{\circ} 1\right)$, y "vigilar el cumplimiento, tanto por parte de las empresas como de los trabajadores" de las medidas de prevención, higiene y seguridad” (art. $66 \mathrm{~N}^{\circ} 2$ ).

${ }^{73}$ Véase: Martin Hernández, María Luisa, Los deberes de los trabajadores, cit. (n. 64), p. 11.

${ }^{74}$ Véase: Montoya Melgar, Alfredo, Los deberes del trabajador en materia de seguridad, cit. (n. 63), p. 52.

${ }^{75}$ Véase: por ejemplo, sentencia de la Corte Suprema de 23 de abril de 1993, en Revista de Derecho y Jurisprudencia y Gaceta de los Tribunales, XC, sección tercera (1993), p. 28.

${ }^{76}$ Véase Martin Hernández, María Luisa, Los deberes de los trabajadores, cit. (n. 64), p. 13 y 25. Y agrega en p. 14: "Los deberes en materia de seguridad y salud en el trabajo impuestos a los trabajadores han sido configurados legalmente, por tanto, como deberes complementarios del deber del empresario de garantizar a todos y cada uno de los trabajadores (...) una protección eficaz frente a los riesgos derivados del trabajo". 
refiere al estándar mínimo de exigencia, sino que también se vincula con el régimen sancionatorio: por regla general, las infracciones del trabajador no se resuelven dentro del ámbito administrativo sancionador (cosa que sí ocurre con el empleador $)^{77}$.

Por último, cabe hacer presente que los deberes de colaboración instrumentales, en materia de seguridad y salud en el trabajo, permiten que el empleador cumpla con sus exigencias legales y contractuales de seguridad ${ }^{78}$. Y por ello, el ordenamiento laboral le reconoce al empleador la legitimidad jurídica para exigir el cumplimiento de estas medidas adoptando, incluso, decisiones de carácter disciplinario ${ }^{79}$. Lo anterior deja al descubierto que uno de los fundamentos del artículo 160 No 5 CT. se encuentra precisamente en las obligaciones de higiene y seguridad que pesan sobre el empleador, ya que en caso de que ellas no se cumplan indefectiblemente él tendrá que responder de estas falencias.

d) La seguridad de los trabajadores. Como se ha dicho, uno de los bienes jurídicos protegidos por la causal del artículo 160 No 5 CT. es la seguridad de los trabajadores. Se trata, desde luego, de la seguridad física y material de éstos; y en el fondo se está exigiendo que en el actuar del trabajador se tenga presente un mínimo de previsibilidad en el riesgo ${ }^{80}$. Si esa previsibilidad no se tiene en cuenta, y en definitiva se obtiene un resultado que afecta la integridad física y material de un sujeto pasivo, entonces deberá entenderse que el infractor faltó a su obligación contractual.

La redacción utilizada por el Código pone el énfasis, desde luego, en la

${ }^{77}$ Una excepción a esta regla general se encuentra en el artículo 70 de la Ley $\mathrm{N}^{\circ}$ 16.744, el cual dispone que si el accidente o enfermedad ocurre debido a negligencia inexcusable de un trabajador entonces "se le deberá aplicar una multa de acuerdo con lo preceptuado en el artículo $68^{\circ}$, aún en el caso de que él mismo hubiere sido víctima del accidente".

${ }^{78}$ Véase: Barrientos Zamorano, Marcelo, La obligación de seguridad en la subcontratación laboral, cit. (n. 62), p. 88.

${ }^{79}$ Véase: Martin Hernández, María Luisa, Los deberes de los trabajadores en materia de seguridad y salud en el trabajo: aspectos materiales y procesales, cit. (n. 64), p. 18. Y agrega en p. 51: "En definitiva, si el empresario en supuestos extremos [...] no adopta como medida de seguridad específica el ejercicio de su poder disciplinario, (entonces) será el empresario el que de forma directa e inmediata incurra en responsabilidad por incumplimiento [...]. En estos supuestos el ejercicio del empresario de su poder disciplinario constituye una medida de seguridad necesaria, técnica y organizativamente factible, para que el empresario pueda cumplir con su deber de garantizar la protección eficaz de sus trabajadores [...]". Véase también y a mayor abundamiento: García Murcia, Joaquín, Responsabilidades y sanciones, cit. (n. 67), pp. 52 ss.

${ }^{80}$ Véase: Barrientos Zamorano, Marcelo, La obligación de seguridad en la subcontratación laboral, cit. (n. 62), p. 87. 
seguridad de los compañeros de labores que prestan servicios en la misma empresa que el infractor. Sin embargo, desde la perspectiva del sujeto activo del deber, el ordenamiento legal le otorga al trabajador obligaciones especiales destinadas a resguardar la mencionada seguridad ${ }^{81}$.

En este contexto, en el diseño del Código los deberes de seguridad no sólo son exigibles al empleador; también el trabajador se encuentra sujeto a ellos. Por eso, en este último caso, el deber de seguridad obliga al trabajador en una doble dimensión: en primer término, a una obligación privada, de carácter contractual, y cuyo incumplimiento puede acarrear el término del vínculo. A fin de cuentas, el no acatamiento de las medidas de seguridad por parte del trabajador supone un riesgo que, por lo demás, no exonera al empleador de las sanciones previstas en caso de no haber ejercido el deber de vigilancia. De allí que la circunstancia de no cumplir, por parte del trabajador, con las exigencias de seguridad que se le imponen en la empresa, deja al descubierto un caso evidente de incumplimiento contractual.

Pero, adicionalmente, este deber de seguridad que debe ejecutar el trabajador también refleja una exigencia jurídico-pública frente al sistema de seguridad social y que consiste en cumplir con la normativa sobre accidentes del trabajo y enfermedades profesionales ${ }^{82}$. Desde luego, el empleador es el obligado a adoptar y vigilar el cumplimiento de las medidas de seguridad que le impone el sistema; pero el trabajador no puede incurrir en desobediencia de esas medidas.

e) La salud de los trabajadores. El término "s a lud" debe ser entendido en términos amplios; es decir, referido al estado en que el organismo del trabajador, y sus funciones, son ejercidas normalmente. Más aun, y de acuerdo a los criterios de los organismos internacionales, la noción clásica de salud ya ha sido superada por un concepto más extenso

${ }^{81}$ Véase por todas sentencias de la Corte Suprema de 28 de abril de 2005, en Gaceta Jurídica, 298 (2005), p. 254; y de 14 de julio de 2010 (causa ingreso corte No 1606-2010, en www.poderjudicial.cl).

${ }^{82}$ Así se desprende, por ejemplo, del artículo 67 de la Ley No 16.744, sobre seguro contra riesgos de accidentes del trabajo y enfermedades profesionales, en cuya virtud los trabajadores estarán obligados a cumplir con las exigencias de seguridad que impongan los reglamentos de la empresa. Y agrega: "Los reglamentos deberán consultar la aplicación de multas a los trabajadores que no utilicen los elementos de protección personal que se les haya proporcionado o que no cumplan las obligaciones que les impongan las normas, reglamentaciones o instrucciones sobre higiene y seguridad en el trabajo". En la misma perspectiva, Véase el artículo 70 de la Ley No 16.744 , el cual sanciona al trabajador en caso de producirse un accidente o enfermedad cuyo origen sea negligencia inexcusable de éste. 
y omnicomprensivo de un estado de completo bienestar físico, mental y social.

Con todo, las afectaciones a la salud del sujeto pasivo de la infracción deben vincularse a las exigencias de higiene y seguridad que perentoriamente se verifican en el ámbito laboral. En esta perspectiva, la norma del artículo 160 No 5 CT. no está pidiendo que el sujeto de la infracción promocione o restablezca un estado de plenitud orgánica y funcional. Simplemente, se quiere que todo trabajador proteja y contribuya a la conservación de la salud tanto propia como de sus compañeros de labores. En último término, las actividades de promoción y restauración de la salud le corresponderán básicamente al empleador y al Estado ${ }^{83}$.

La casuística jurisprudencial del artículo 160 No 5 CT., no es demasiado abundante al momento resolver eventuales atentados cometidos por un trabajador en este ámbito. Sin embargo, en varios procesos judiciales de despido indirecto, los demandantes han accionado en contra de su empleador por incurrir precisamente en infracción a la norma del artículo $160 \mathrm{~N}^{\circ} 5 \mathrm{CT}$. Así, por ejemplo, se ha concluido que concurre omisión e imprudencia temeraria del demandado cuando mantiene al trabajador en un ambiente saturado de polvo y otros elementos tóxicos que, en definitiva, le produjeron graves y perniciosas consecuencias para su salud, desde que le fue diagnosticada silicosis. De este modo, se produce una infracción al artículo $184 \mathrm{CT}$. ya que no se adoptan todas las medidas necesarias para proteger eficazmente la vida y la salud de los trabajadores ${ }^{84}$.

\section{CONCLUSIONES}

Los puntos que resumen las conclusiones de este trabajo, son los siguientes:

$1^{\circ}$ El Código del Trabajo sanciona los actos, omisiones o imprudencias temerarias que ejecute el trabajador, y que afecten bienes jurídicos relevantes que el propio legislador se ha encargado de reseñar. Estas conductas no suponen la comisión de un delito, ya que laboralmente ellas deben ser vistas de manera más amplia y no como un concepto técnico jurídico-penal.

$2^{\circ}$ La norma del artículo 160 No 5 CT. sanciona tanto las conductas dolosas como culposas. De esta manera, el precepto legal utiliza una cierta degradación de gravedad entre los actos, omisiones e imprudencias teme-

${ }^{83}$ Véase Palomeque López, Manuel Carlos, Los derechos a la seguridad social y a la salud en la Constitución, en Derecho del Trabajo y de la Seguridad Social en la Constitución (Madrid, Centro de Estudios Constitucionales, 1980), p. 332.

${ }^{84}$ Véase: sentencia de la Corte Suprema de 29 de enero de 2008 (causa ingreso corte $\mathrm{N}^{\circ}$ 5131-2007, en www.poderjudicial.cl). 
rarias, permitiendo concluir que los actos u omisiones pueden ser dolosos o culposos. La imprudencia temeraria, por el contrario, claramente exige un determinado nivel de culpa. Esta degradación en la estructura de la norma permite concluir, además, que se encuentran fuera de esta hipótesis extintiva las conductas meramente negligentes, y que son menos intensas que la imprudencia temeraria.

$3^{\circ}$ A diferencia de lo que ocurre en otras causales disciplinarias, el artículo 160 No 5 CT. no exige un resultado perjudicial para probar la infracción. Por el contrario, el Código sólo exige una alteración mínima que traiga como consecuencia la afectación de ciertos bienes jurídicos. Por ello, el vocablo afectar no puede ser visto como un sinónimo de producción cierta de un daño, sino sólo como la posibilidad concreta de que ese perjuicio de produzca.

$4^{\circ}$ Los bienes jurídicos resguardados por la norma del artículo 160 No 5 CT. se han establecidos de forma genérica, pero no a título ejemplar. En esta perspectiva, el legislador resguarda la seguridad o el funcionamiento del establecimiento (y no de la empresa). Para estos efectos, el establecimiento debe ser configurado como una unidad técnica de producción, que se diferencia de la unidad económica productiva que sería la empresa propiamente tal. Más aun, el establecimiento no puede ser asociado al dato geográfico ya que lo distintivo del concepto laboral de establecimiento es su expresión organizativa.

$5^{\circ} \mathrm{La}$ actividad de los trabajadores, en cuanto bien jurídico protegido por la hipótesis extintiva, se vincula con las tareas $\mathrm{u}$ operaciones propias de cada trabajador dentro de la organización empresarial. Por tanto, la causal disciplinaria no cubre afectaciones relacionadas con tareas ajenas al ámbito contractual. De allí que el estándar de no afectación exigido es aquél que normalmente cabría pedirle al trabajador en el desempeño de sus funciones regulares.

60 El resguardo de la seguridad y salud en el trabajo lleva a relacionar este supuesto extintivo con deberes de colaboración instrumental por parte del trabajador, que le permiten al empleador responder de su condición de deudor de seguridad. Estos deberes de colaboración se manifiestan en medidas de autoprotección, en el cumplimiento de medidas generales de protección y en deberes de colaboración. La hipótesis del artículo 160 No 5 CT. sanciona precisamente el incumplimiento de estos deberes instrumentales. 


\section{BIBLIOGRAFÍA}

BARRIENTOS ZAMORANO, Marcelo, La obligación de seguridad en la subcontratación laboral: previsibilidad del hecho y del daño, en Revista Chilena de Derecho, 39 (2012) 1.

Cabanellas, Guillermo, Tratado de Derecho Laboral ( $3^{a}$ edición Buenos Aires, Heliasta, 1988), II.

CANO GALÁN, Yolanda, La formación en prevención de riesgos laborales: su configuración como deber de los trabajadores, en Revista del Ministerio de Trabajo y Asuntos Sociales, 53 (2004).

Davis, Pedro, Terminación del contrato de trabajo (Santiago, Editorial Bibliográfica Chilena, s.d.).

Cristóbal Roncero, María del Rosario, Los derechos de los trabajadores en la transmisión de empresas. Estudio del ordenamiento jurídico alemán (Madrid, Servicio de Publicaciones Facultad de Derecho, Universidad Complutense de Madrid, 1999).

García MurCia, Joaquín, Los incumplimientos del trabajador en materia de seguridad y salud en el trabajo como causa de despido disciplinario, en GÁrATE CASTRO, Javier (coordinador), Cuestiones actuales sobre el despido disciplinario (Santiago de Compostela, Universidad de Santiago de Compostela, 1997).

García Murcia, Joaquín, Responsabilidades y sanciones en materia de seguridad y salud en el trabajo (Pamplona, Aranzadi, 1998),

Garrido Montt, Mario, Derecho penal (4a edición, Santiago Editorial Jurídica de Chile, 2010), II.

Goerlich Peset, José María, Particularidades de la responsabilidad indemnizatoria del trabajador por los daños causados a la empresa en el desarrollo de la prestación laboral: un intento de explicación, en Revista Española de Derecho del Trabajo, 152 (2011).

González Biedma, Eduardo, El cambio de titularidad de la empresa en el derecho del trabajo (Madrid, Centro de Publicaciones Ministerio del Trabajo y Seguridad Social, 1989).

GonZÁlez Ortega, Santiago, Seguridad y salud en el trabajo (en torno al artículo 19), en Revista Española de Derecho del Trabajo, 100 (2000) 1.

Historia Fidedigna de la Ley No 19.010 (Primer Informe Comisión de Constitución, Legislación, Justicia y Reglamento y de Trabajo y Previsión Social, unidas, del Senado, de 8 de agosto de 1990).

Humeres Noguer, Héctor (director), Repertorio de Legislación y Jurisprudencia Chilenas. Código del Trabajo y Leyes Complementarias (Santiago, Editorial Jurídica de Chile, 2002), I.

Irureta Uriarte, Pedro, Empresa y personalidad juridica, en Revista Persona y Sociedad, 16 (2002) 1.

Labatut Glena, Gustavo, Derecho penal (7a edición, Santiago, Editorial Jurídica de Chile, 1996), I.

Martin Hernández, María Luisa, Los deberes de los trabajadores en materia de seguridad $y$ salud en el trabajo: aspectos materiales y procesales, en Estudios Jurídicos (2006).

Miñambres Puig, César, El Centro de Trabajo (Madrid, Servicio de Publicaciones Ministerio de Trabajo y Seguridad Social, 1985).

Monereo Pérez, José Luis, Las relaciones de trabajo en la transmisión de la empresa (Madrid, Servicio de Publicaciones Ministerio de Trabajo y Seguridad Social, 1987).

Monereo Pérez, José Luis, Teoría jurídica de los grupos de empresas y derecho del trabajo (Granada, Comares, 1997). 
Monereo Pérez, José Luis, La transmisión parcial de empresa: el "centro de trabajo" y la "unidad productiva autónoma" de la empresa, en Documentación Laboral, 52 (1997).

Montoya Melgar, Alfredo, Dirección y control de la actividad laboral, en Borrajo DACRUZ, Efrén (director), Comentarios a las leyes laborales. El Estatuto de los Trabajadores (Madrid, Edersa, 1985), V.

Montoya Melgar, Alfredo, Los deberes del trabajador en materia de seguridad en el trabajo y la sanción de su incumplimiento, en GÁRATE CASTRO, Javier (coordinador), Cuestiones actuales sobre el despido disciplinario (Santiago de Compostela, Universidad de Santiago de Compostela, 1997).

Montoya Melgar, Alfredo, Derecho del trabajo (29a edición, Madrid, Tecnos, 2008).

Núnez González, Cayetano, Prevención de riesgos laborales en Chile (2a edición, Santiago, Librotecnia, 2014).

Ortiz Lallana, M. Carmen, Causas y formas del despido disciplinario (en torno a los artículos 54 y 55). El Estatuto de los Trabajadores veinte años después, en Revista Española de Derecho del Trabajo, 100 (2000) 1.

Palomeque López, Manuel Carlos, Los derechos a la seguridad social y a la salud en la Constitución, en Derecho del Trabajo y de la Seguridad Social en la Constitución (Madrid, Centro de Estudios Constitucionales, 1980).

Ramírez Martínez, Juan Manuel - Sala Franco, Tomás, El centro de trabajo: configuración legal, en BORRAJO DACRUZ, Efrén (director), Comentarios a las Leyes Laborales. El Estatuto de los Trabajadores (Edersa, Madrid, 1985), I.

Rivero LAmas, Juan, Limitación de los poderes empresariales y democracia industrial (Zaragoza, Secretariado de Publicaciones, Universidad de Zaragoza, 1986).

RupreCHT, Alfredo, Concepto de empresa, establecimiento y explotación, en Revista del Instituto de Derecho del Trabajo e Investigaciones Sociales, X, 18 (1974).

Sala Franco, Tomás - Ramírez Martínez, Juan Manuel, El concepto de Centro de Trabajo, en Actualidad Laboral, 33 (1985).

Soto Calderón, Juan Carlos, Derecho penal del trabajo (Santiago, Editorial Jurídica de Chile, 1961).

Thayer Arteaga, William - Novon Fuenzalida, Patricio, Manual de derecho del trabajo ( $3^{a}$ edición, Santiago, Editorial Jurídica de Chile, 1998), III.

Walker Errázuriz, Francisco, Terminación del contrato de trabajo (Santiago, Cepet, 1990). 